\title{
The efficiency of the healthcare systems in EU countries - A DEA analysis
}

\author{
GHEORGHIŢA DINCĂ, MARIUS SORIN DINCĂ* (1) and MARIA \\ LETIŢIA ANDRONIC
}

Department of Finance, Accounting and Economic Theory, Faculty of Economic Sciences and Business Administration, Transilvania University of Braşov, B-dul Eroilor 29, Braşov 500036, Romania

Received: May 28, 2018 • Revised manuscript received: February 21, 2019 • Accepted: July 08, 2019

(C) 2020 Akadémiai Kiadó, Budapest

\section{ABSTRACT}

The objective of this paper is to identify the most efficient healthcare systems in a sample of $17 \mathrm{EU}$ Member States. According to the health system financing schemes, the selected countries belong to two main groups, Beveridge and Bismarck. The research includes five input variables describing the financial and human resources, the level of health infrastructure, the medical technology and the healthcare utilization. On the output side we analysed four measures that reflect the overall health status of the population and the effectiveness of prevention and emergency care. Using the Data Envelopment Analysis (DEA) method, the most efficient healthcare systems are found in Sweden, the UK and Romania. The constraints applied for all the indicators and scenarios lead to higher or lower inefficiency scores, the Beveridge group being on average more efficient than the Bismarck one.

\section{KEYWORDS}

healthcare system, Data Envelopment Analysis, efficiency scores, efficiency frontier

\section{JEL CLASSIFICATION INDICES}

H21, H51, H75, I11, I18

\footnotetext{
*Corresponding author. E-mail: marius.dinca@unitbv.ro
} 


\section{INTRODUCTION}

This study aimed to identify the most efficient healthcare systems using a sample of $17 \mathrm{EU}$ states. The health sector is an area where public expenditures are of a great importance so that the findings of this study would have strong implications on public sector's efficiency.

In order to establish the degrees of efficiency and inefficiency of the national health systems we used the Data Envelopment Analysis (DEA). ${ }^{1}$ DEA is also used to identify the countries that have the highest correlation between different resources (financial, technological, and human) allocated for the healthcare system and the results obtained with respect to several variables, such as the perceived health status or the effectiveness of prevention, chronic disease management and emergency care.

We started our analysis by identifying a few indicators regarding the health resources supplied (input) and the health services provided (output). Our final aim is to create a synthetized model, an 1-input/1-output approach, built on the standardized, and then, averaged values of the five inputs, respectively of the four outputs. Our general purpose is to identify the efficient countries in correlation with their health system financing schemes, their geographical position and their EU status of being old or new members and to discuss some improvements we find reasonable to be applied for the least efficient states. We have also established a ranking of the selected 17 countries.

The rest of the paper is structured as follows: Section 2 presents relevant references found in specific literature regarding the way DEA was used in the health sector and elsewhere. In Section 3 , we briefly underlined some characteristics of the health systems in the European countries. Section 4 refers to the methodological aspects regarding the mathematical model applied to process the input and output information and offers a description of the indicators considered in the analysis; Section 5 offers the results and the discussions, while the conclusions are found in the last part.

\section{LITERATURE REVIEW}

Research papers studying expenditure performance often use Free Disposable Hull (FDH) model for efficient measurement and measure the input variables only in monetary terms. Regarding the output analysis, like in the research paper of Afonso et al. (2005), we intended to measure the degree of inefficiency. The objective of reaching performances characterises not only the public sector, but also the private one. At microeconomic level, low economic efficiency produces immediate negative effects and might be reflected, eventually, even in the insolvency of the companies from different sectors (Dincă et al. 2017). As presented by Baba (2016), having a successful public-private partnership in different industries, such as pharmaceutical or textiles, is a major signal for the internal and external factors operating in such markets.

\footnotetext{
${ }^{1}$ Editor's note: The same method is applied in the paper of Kozun-Cieślak "Is the efficiency of the healthcare system linked to the country's economic performance? Beveridgeans versus Bismarckians” in the present issue of Acta Oeconomica.
} 
However, quite frequently, private sector entities are concerned with minimizing the costs and paying taxes. As a result, the private sector becomes reluctant and less interested in supporting the public sector in delivering goods or services. In this context, Trifan and Baba (2009) highly recommend that companies should aim at diversifying the means of calculating their costs to make better predictions and improve their financial performance. If the public-private partnership is encouraged, then companies might get more involved in providing goods and services and citizens' satisfaction is likely to increase.

The access to good quality public and social services is essential for daily life, for the economic and social wellbeing. (Dincă et al. 2016) argue that efficiency and sustainability are essential to make sure that beneficiaries receive the best possible services, corruption is minimized and central and local economy can benefit. One year later, highlighting public money's illegal use, bureaucracy, bribery and corruption, the same authors (Dincă et al. 2017: 78) argue that these extended phenomena bring about poverty and a low quality of public goods and services. As a consequence, citizens have to bear higher taxes as state resources are no longer sufficient to cover all needs, including the provision of basic health services. Moreover, as described by Pîrvu (2015), corruption in public procurement is one major problem widely recognised at European level, which in many countries was caused by tainting the public contract award process. The study of Pîrvu provides empirical evidence that between 2009-2013 many "political companies" repeatedly won public procurement contracts and did business only or almost only with local and central authorities (contracting authorities who represent the interests of political parties).

Varabyova - Schreyögg (2013) performed panel-data analysis and found that higher health expenditures influence the efficiency in the hospital sector. Cheng - Zervopoulos (2014) used a generalised directional distance function to measure health systems' efficiency from 171 states. They employed a methodology which introduced a modified definition of the efficiency score, producing results consistent with those obtained from the radial DEA models. There are studies describing that the costs of diseases increase exponentially for elderly people. Thomson - Mossialos (2009) shows that each citizen over 60 years suffers from an average of 2.2 chronic diseases. DEA was used to assess different aspects of the medical field: health facilities - Hollingsworth (2008) and Ferrier et al. (2006), and hospital and physicians' clinical efficiency - Nedelea et al. (2010) and Chilingerian (1995). In the DEA literature, the institutions that make the most important health policy decisions and through this determine the system's efficiency are called DMUs (decision making units).

The DEA articles studying health efficiency often show that the efficient countries are the ones with a solid economy. However, when studying input efficiency of healthcare systems for 2010, using a sample of 30 European countries, Asandului et al. (2014) revealed that Romania and Bulgaria were among the more efficient systems, although these countries' general economic performances are poor. A similar conclusion was also reached by Kozuń-Cieślak (2020) who examined the Bismarckian and Beveridgean-style healthcare systems in 25 OECD countries to identify the relationship between the efficiency of the country's healthcare delivery arrangement and its economic wealth. Three different input models were examined (in terms of expressing the healthcare inputs), each of them using the infant mortality and potential years of life lost as output indicators. The analysis of the relationship between the DEA scores and the country's GDP per capita showed that more developed economies are less efficient, these findings being consistent with the belief that technical efficiency is only one of the many criteria which influence the quality of the healthcare system and patient satisfaction.

Medeiros - Schwierz (2015) applied DEA to establish the efficiency for all EU Member States. The selected outputs were life expectancy and amenable mortality rates, whereas the inputs were 
per capita health expenditures, physical and environmental variables. The results showed that life expectancy could grow by 1.8 years when moving from effective positions to the efficiency frontier.

Governments are engaged in financing medical care. Doboş (2008: 107) showed that most EU Member States, instead of a single source for funding, use a dual funding, in which social contributions and direct financing are complementary. The health system's efficiency became a constant subject for the specialists looking to find the optimal allocation of financial resources to generate the best results. Using time series for 34 years, Zee - Kroneman (2007) studied the performances of the two health systems, National Health Services (NHS) and Social Security Health (SSH), as they were designed by their founding parents, Beveridge and Bismarck respectively, for several European states. The output variables were infant mortality rate and life expectancy at birth, whereas the inputs were the healthcare expenditures. The results did not show major differences between the two forms of organising the health systems and support the idea that health policy should concentrate on the quality of outputs. Health systems' efficiency was also studied by Evans et al. (2001) for 191 states for five years (19931997). Considering the impact of education upon the level of health, they have included a measure expressing the number of years of schooling of the adult population. The results showed a connection between health spending and efficiency, especially in the states with lower levels of expenditures.

In many Central and Eastern European states, the economic disparities between different regions and other subnational levels are still evident. When describing the efficiency of public expenditures for the larger Romanian municipalities, Andronic (2015: 47) found that the public sector's efficiency becomes more important in the context of decentralizing policies designed to refocus public decision-making from central to the lower levels of local governments.

The novelty of our research comes from the fact that we discuss the efficiency scores by referring to several dimensions related to the financing schemes of the selected countries' health system, their geographic position and their status of being old or new members of the EU. Another contribution is that we introduced a total input indicator, Global Input Measure (GIM) and a total output indicator, Global Output Measure (GOM). The two computed measures enabled us to identify the efficiency scores for each country.

\section{HEALTH SYSTEMS IN THE EU}

In this study, we have selected $17 \mathrm{EU}$ states and divided them according to the criteria of financing the health system. Thus, there are two categories:

1. Bismarck-type countries: Austria, Belgium, Czech Republic, Luxembourg, France, Germany, Hungary, Poland, Romania, Slovenia. These countries will be referred to as the social security contribution (SSC) or Bismarck group of countries.

2. Beveridge-type countries: Denmark, Finland, Italy, Portugal, Spain, Sweden and the UK. This category will be addressed as the direct tax (DT) or Beveridge group.

Besides the funding criteria, our research includes other dimensions as well. First, we considered the year in which each state joined the EU. As a result, we have two categories:

1. The old member-states (before 2004): Austria, Belgium, Denmark, Italy, Finland, France, Germany, Luxembourg, Portugal, Spain, Sweden, the UK; 
2. The new member-states: Czech Republic, Hungary, Poland, Romania, Slovenia.

Second, we studied whether there is a correlation between efficiency and the geographic position of the countries in Europe ${ }^{2}$.

1. The Northern group: Denmark, Finland and Sweden;

2. The Western group: Belgium, France, Luxembourg and the UK;

3. The Southern group: Italy, Portugal and Spain;

4. The Central European group: Austria, Czech Republic, Germany, Hungary, Poland, Romania and Slovenia.

\section{THEORETICAL APPROACH AND METHODOLOGY OF DEA}

DEA is a method in which the concept of efficiency relies on comparison. Its foundations go back to Farrel (1957). DEA is more often applied to estimate the efficiency of the public sector DMUs and to define their ability to produce goods or to provide public services as near as possible to the convex efficiency frontier. In essence, the model assumes two working hypotheses: restricting the weighted outputs' sum in order to minimize the input volume (input orientation) and restricting the weighted inputs' sum in order to maximize the results (output orientation).

The system of inequalities used to describe the specific constraints of an input-oriented model is the following: $\min \theta$,

$$
\left\{\begin{array}{l}
Y_{k} \lambda \geq y_{k i} \\
X_{j} \lambda \leq \theta x_{j i} \\
\sum_{i=1}^{n} \lambda_{i}=1 \\
\lambda \geq 0,
\end{array}\right.
$$

where:

- $\theta$ is a scalar whose value $(\theta \leq 1)$ reflects the efficiency of the $i$ decision unit; the calculus of this scalar will be performed $n$ times for each decision unit;

- $\lambda$ is a vector of positive constraints, indicating the weight of the restrictions;

- $\theta$ and $\lambda$ are variables whose values will change after processing the input and output data to observe the requirements imposed by the inequalities system;

- $y_{k i}$ is the output value of the $k$ variable registered for the $i$ unit;

- $Y_{k} \lambda$ is a value determined for the $n$ units as a sum of the products between the output value of the $k$ variable and the vector indicating the specific weights; the procedure is repeated for each $k$ output variable $(k=1, \ldots, s): \sum_{i=1}^{n} y_{k i} \times \lambda_{i}$;

- $X_{j} \lambda$ is a value determined for the $n$ units as a sum of the products between the input value of the $j$ variable and the vector indicating the specific weights; the procedure is repeated for each $j$ input variable $(j=1, \ldots, m): \sum_{i=1}^{n} y_{k i} \times \lambda_{i} \sum_{i=1}^{n} y_{k i} \times \lambda_{i}$;

\footnotetext{
${ }^{2}$ Some states are not necessarily just Northern, Western, Southern or Central European. However, we placed these countries into the most suitable group to avoid creating too many categories.
} 
- $\theta x_{j i}$ is the efficiency of the product between $\theta$ and $j$ value registered for unit $i$.

According to Coelli (1996), input-oriented efficiency addresses the question: "By how much can input quantities be reduced without changing the output quantities?" One could alternatively ask: "By how much can output quantities be expanded without altering the input quantities used?" Both questions are relevant. This is the reason why we consider that both the models should be included in the DEA analysis.

An output-oriented DEA model is described by the following constraints: $\max \Phi$,

$$
\left\{\begin{array}{l}
Y_{k} \lambda \geq \Phi y_{k i} \\
X_{j} \lambda \leq x_{j i} \\
\sum_{\substack{i=1 \\
\lambda \geq 0}}^{n} \lambda_{i}=1
\end{array}\right.
$$

where:

- $\Phi$ is a scalar whose value $(1 \leq \Phi<\infty)$ will contribute to $i$ decision unit efficiency's determination and of the proportional increase that can be brought to the output measures, maintaining constant the input level for each DMU; the calculus of this scalar will be performed $n$ times for each DMU;

- $1 / \Phi$ is the score defining the below par level of technical efficiency $(0<1 / \Phi \leq 1)$;

- $\Phi$ and $\lambda$ are the variables whose values are modified after processing the inputs and outputs to comply with the requirements imposed by the inequalities system;

- $x_{j i}$ is the input value of the $j$ variable registered by the $i$ unit;

- $\Phi y_{k i}$ is the efficiency described by the product of $\Phi$ and $k$ variables of the $i$ unit.

Since the computation uses linear programming, both orientation models identify the same set of efficient and inefficient DMUs. However, the scores associated with the inefficient units can be different (Afonso - Fernandes 2006).

The study of both input and output cases offers a complete image in determining the overall efficiency of the DMUs. The whole paper distinguishes between the two scenarios. It is a very good approach as the main focus of political debate is double. For the input side, the attention focuses on the ability to reduce the applied resources of the healthcare systems, and not only the expenditures, but all the other resources. The output orientation is assimilated to the improvement and potential growth of the outcome part of the healthcare systems. It is recommended to analyse also this perspective in order to identify how much the outputs may increase by using a given amount of inputs.

After studying the relevant literature, we kept the following as input variables: health spending as ratio in GDP, number of health personnel per 100,000 inhabitants divided into two categories: medical doctors and other personnel, number of acute care hospital beds per 100,000 inhabitants, number of Computer Tomography (CT) and Magnetic Resonance Imaging (MRI) machines per 1,000,000 inhabitants and number of doctor consultations per inhabitant.

The only financial input indicator included in the analysis is the total amount spent for healthcare as a share of GDP. In the paper, as it is customary in the literature, this measure refers to the funds allocated both to public health systems and to the private ones. It seems to be quite 
correct to include both systems in the analysis as the private sector has a growing importance in several of the observed countries. For instance, in the developing countries such as Romania, there is a significant growth of the private health sector for the general medicine cabinets, dental offices, polyclinics, medical centres, pharmaceutical points and drugstores.

Regarding the health personnel, we divided the total staff number in two types: physicians and other personnel. Physicians diagnose, treat and prevent illness and other physical and mental impairments through the procedures of modern medicine. According to the WHO standards, they conduct medical education and research. The group of other health staff includes dentists, pharmacists, physiotherapists, nurses and midwives.

The number of hospital beds expresses the system's level of infrastructure. The variable is used as a proxy of the infrastructure's size for describing the capacities of the health systems. We used only the category of acute or short-term care beds as it seems more homogenous than studying any kind of beds.

The two non-financial input measures described so far are expressed in population-standardized rates (per 100,000 inhabitants) and refer to human resources and technical capacity dimensions.

The technological background was referred to through two proxies of it: number of CT scanners and MRI machines. These technologies are employed on a large scale for the diagnosis of diseases and monitoring the patients. We considered the equipment used in hospitals and by the providers of ambulatory healthcare and expressed it as the number of machines per $1,000,000$ citizens.

For the healthcare utilization category, we introduced the number of consultations of a medical doctor (in private practice or as outpatient) per inhabitant. This variable shows the effectiveness of the huge number of consultations at physician offices. Data retrieved from Eurostat refer to the medical speciality of generalist and specialist medical practitioners.

The output measures are: the infant survival rate per 1,000 live births, good or very good selfperceived health status (percentage within the population over 16), life expectancy at birth and potential years of life lost (number of years).

The infant survival rate expresses the overall effectiveness of the maternity and paediatric care. It was established by deducting the infant mortality rate from 1,000. The infant mortality rate per 1,000 live births is calculated as the ratio of number of deaths of children under one to the number of births. This variable is quite specific for the assessment of efficiency of the maternity and paediatric care. Still, it does not reflect the long-term healthcare for the adult and elderly people that comprises of the vast majority of the health resources and costs.

Life expectancy at birth is one of the indicators that express the overall health status of the population. The final aim of the healthcare sector is the improvement of life expectancy and the quality of life. The recorded values are an average number of years of life expectancy at birth of males and females.

The self-perceived health indicator is one of the three different concepts of health status. The concept of the self-perceived health is operationalised by a question on how a person perceives his/her health using one of the answer categories: very good, good, fair, bad or very bad. We took into account the share of the total population over 16 whose answer was "good" or "very good".

The potential years of life lost is a measure of premature mortality which provides a way of weighting deaths occurring at younger ages which might have been prevented. It is established 
by adding up deaths occurring at each age up to 70, multiplying this with the number of remaining years to live until 70 and then dividing this by the midterm population. Last, the term is standardized using the European Standard Population. In order to show good characteristics, we analysed the inverse of the potential life years of life lost as a proxy of effectiveness of prevention, chronic disease management and emergency care.

It is mandatory to get higher explanatory power for the outputs by referring as complete as possible to the results of the resources allocated for infants, of the treatment for adults and elderly people or of chronic disease management.

The methodology used involved a step by step study for each decision unit (country), both from an input and an output perspective, using the computed GIM and GOM scenarios. In the next part we will explain the methodology applied in order to create the synthetized scenario of 1-input and 1-output.

First, for transforming a heterogeneous unit of measurement series of data, we normalised the values of each of the five inputs and four outputs by setting the average equal to 1 . Second, we recalculated each sub-indicator relative to the overall average and obtained index values (below or above the average of 1) instead of percentages, number of years, personnel, beds, doctor consultation or medical machines. Finally, we computed a single input measure (GIM), and one output measure (GOM). We considered each indicator to have an equal weight and created an average index value for each country, for input and for output. Table 1 reflects the index values for the nine indicators and the synthesized results. Two of the input indicators, health personnel and medical technology, were built as an average of the sub-indicators they comprise: physicians and other health staff, respectively CT scanners and MRI machines.

Besides the actual index values and the averages for all categories of countries, the standard deviation (SD) is also displayed. The lowest SD value characterizes the infant survival rate index because there are insignificant differences between countries, the average number of surviving children under 1 at 1,000 live births being above 994 for all countries, except for Romania, which had a 16-year average value of 987 . The highest SD value (0.5194) belongs to the input variable describing the number of CT scanners and MRI machines per 1,000,000 citizens. The most far away state from the average is Germany with an index of 2.0184, while at the opposite side, but still far from the average, we find Romania with an index of 0.2468.

The average index values for the Beveridge group indicate values of above 1 for all outputs, including GOM (1.0503). The Bismarck countries seem to be above average for the acute care hospital beds, for the consultations of a doctor and for the GIM (1.0307). These results might suggest that the countries financed mostly through direct taxes are more efficient resource users than the others. The DT system uses below average resources and gets above average results.

With respect to the other dimensions, we may state that:

- Most of the former EU states use above average inputs and obtain above average outputs, while most new Member States use below average inputs and obtain about the same low results reflected through GOM;

- Western and Southern European countries record a desired combination between inputs and outputs: the average GIM below 1 and the average GOM above 1;

- Northern countries prove to be on average a bit too resource-consuming (1.0096); still, these states offer the highest levels of services for their citizens (1.0638); 
Table 1. Index values of the 5 input and 4 output measures and the computed GIM and GOM indices

\begin{tabular}{|c|c|c|c|c|c|c|c|c|c|c|c|}
\hline \multirow[b]{2}{*}{$\begin{array}{l}\text { Decision } \\
\text { unit }\end{array}$} & \multicolumn{5}{|c|}{ Input variables' index } & \multicolumn{4}{|c|}{ Output variables' index } & \multirow[b]{2}{*}{$\begin{array}{c}\text { GIM } \\
\text { index }\end{array}$} & \multirow[b]{2}{*}{$\begin{array}{l}\text { GOM } \\
\text { index }\end{array}$} \\
\hline & $\begin{array}{c}\text { Health } \\
\text { expenditures }\end{array}$ & $\begin{array}{c}\text { Health } \\
\text { personnel }\end{array}$ & $\begin{array}{c}\text { Acute } \\
\text { care } \\
\text { hospital } \\
\text { beds }\end{array}$ & $\begin{array}{c}\text { CT and } \\
\text { MRI } \\
\text { machines }\end{array}$ & $\begin{array}{l}\text { Consultations } \\
\text { of doctors }\end{array}$ & $\begin{array}{c}\text { Life } \\
\text { expectancy }\end{array}$ & $\begin{array}{c}\text { Infant } \\
\text { survival } \\
\text { rate }\end{array}$ & $\begin{array}{c}\text { Self- } \\
\text { perceived } \\
\text { health } \\
\text { status }\end{array}$ & $\begin{array}{l}\text { Inverse of } \\
\text { potential } \\
\text { years of life } \\
\text { lost }\end{array}$ & & \\
\hline Austria & 1.1960 & 1.1416 & 1.4720 & 1.6600 & 1.0311 & 1.0162 & 1.0005 & 1.0654 & 1.1002 & 1.3001 & 1.0456 \\
\hline Belgium & 1.0904 & 1.1738 & 1.3169 & 1.0380 & 1.0586 & 1.0102 & 1.0005 & 1.1190 & 0.9995 & 1.1356 & 1.0323 \\
\hline Czech Rep. & 0.9056 & 1.0461 & 1.1787 & 0.5991 & 1.8246 & 0.9757 & 1.0012 & 0.9141 & 0.8552 & 1.1108 & 0.9366 \\
\hline Denmark & 1.2824 & 1.3447 & 0.8000 & 1.2111 & 0.6817 & 0.9989 & 1.0004 & 1.1207 & 1.0576 & 1.0640 & 1.0444 \\
\hline Finland & 0.9447 & 1.1689 & 0.8200 & 1.3271 & 0.6478 & 1.0110 & 1.0017 & 1.0468 & 1.0094 & 0.9817 & 1.0172 \\
\hline France & 1.2514 & 1.0011 & 0.8404 & 0.5936 & 1.0320 & 1.0277 & 1.0005 & 1.0358 & 0.9767 & 0.9437 & 1.0102 \\
\hline Germany & 1.2249 & 1.2558 & 1.4885 & 2.0184 & 1.3454 & 1.0126 & 1.0006 & 0.9570 & 1.0362 & 1.4666 & 1.0016 \\
\hline Hungary & 0.7717 & 0.8336 & 1.1854 & 0.3403 & 1.7415 & 0.9382 & 0.9984 & 0.7920 & 0.5794 & 0.9745 & 0.8270 \\
\hline Italy & 0.9850 & 1.0462 & 0.7576 & 1.6912 & 0.9661 & 1.0341 & 1.0010 & 0.9646 & 1.3548 & 1.0892 & 1.0886 \\
\hline Luxembourg & 0.9517 & 0.9578 & 1.0550 & 1.2008 & 0.8980 & 1.0153 & 1.0009 & 1.1049 & 1.2075 & 1.0127 & 1.0821 \\
\hline Poland & 0.6675 & 0.6868 & 1.1430 & 0.4505 & 1.0014 & 0.9604 & 0.9985 & 0.8580 & 0.6200 & 0.7898 & 0.8592 \\
\hline Portugal & 0.9744 & 0.7825 & 0.8020 & 1.1499 & 0.6071 & 1.0048 & 1.0007 & 0.7134 & 0.9874 & 0.8632 & 0.9266 \\
\hline Romania & 0.6309 & 0.6761 & 1.1535 & 0.2468 & 0.7206 & 0.9255 & 0.9916 & 1.0510 & 0.5219 & 0.6856 & 0.8725 \\
\hline Slovenia & 0.9536 & 0.8193 & 1.0659 & 0.6398 & 0.9593 & 0.9971 & 1.0013 & 0.8963 & 1.0281 & 0.8876 & 0.9807 \\
\hline Spain & 0.9142 & 0.9081 & 0.6090 & 0.8925 & 1.2489 & 1.0318 & 1.0009 & 1.0629 & 1.2739 & 0.9145 & 1.0924 \\
\hline Sweden & 0.2199 & 1.2451 & 0.6070 & 1.4047 & 0.4392 & 1.0288 & 1.0016 & 1.1585 & 1.3303 & 0.9832 & 1.1298 \\
\hline UK & 1.0360 & 0.9126 & 0.7053 & 0.5361 & 0.7966 & 1.0117 & 0.9997 & 1.1397 & 1.0618 & 0.7973 & 1.0533 \\
\hline Stand. dev. & 0.1958 & 0.2025 & 0.2817 & 0.5194 & 0.3744 & 0.0320 & 0.0023 & 0.1288 & 0.2429 & 0.1900 & 0.0881 \\
\hline
\end{tabular}


Table 1. Continued

\begin{tabular}{|c|c|c|c|c|c|c|c|c|c|c|c|}
\hline \multirow[b]{2}{*}{$\begin{array}{l}\text { Decision } \\
\text { unit }\end{array}$} & \multicolumn{5}{|c|}{ Input variables' index } & \multicolumn{4}{|c|}{ Output variables' index } & \multirow[b]{2}{*}{$\begin{array}{l}\text { GIM } \\
\text { index }\end{array}$} & \multirow[b]{2}{*}{$\begin{array}{l}\text { GOM } \\
\text { index }\end{array}$} \\
\hline & $\begin{array}{c}\text { Health } \\
\text { expenditures }\end{array}$ & $\begin{array}{c}\text { Health } \\
\text { personnel }\end{array}$ & $\begin{array}{c}\text { Acute } \\
\text { care } \\
\text { hospital } \\
\text { beds }\end{array}$ & $\begin{array}{c}\text { CT and } \\
\text { MRI } \\
\text { machines }\end{array}$ & $\begin{array}{l}\text { Consultations } \\
\text { of doctors }\end{array}$ & $\begin{array}{c}\text { Life } \\
\text { expectancy }\end{array}$ & $\begin{array}{c}\text { Infant } \\
\text { survival } \\
\text { rate }\end{array}$ & $\begin{array}{c}\text { Self- } \\
\text { perceived } \\
\text { health } \\
\text { status }\end{array}$ & $\begin{array}{l}\text { Inverse of } \\
\text { potential } \\
\text { years of life } \\
\text { lost }\end{array}$ & & \\
\hline Avg SSC & 0.9644 & 0.9592 & 1.1899 & 0.8787 & 1.1613 & 0.9879 & 0.9994 & 0.9793 & 0.8925 & 1.0307 & 0.9648 \\
\hline Avg DT & 1.0509 & 1.0583 & 0.7287 & 1.1732 & 0.7696 & 1.0173 & 1.0009 & 1.0295 & 1.1536 & 0.9562 & 1.0503 \\
\hline Avg old EU & 1.0892 & 1.0782 & 0.9395 & 1.2270 & 0.8961 & 1.0169 & 1.0008 & 1.0407 & 1.1163 & 1.0460 & 1.0437 \\
\hline Avg new EU & 0.7858 & 0.8124 & 1.1453 & 0.4553 & 1.2495 & 0.9594 & 0.9982 & 0.9023 & 0.7209 & 0.8896 & 0.8952 \\
\hline Avg $N$ & 1.1490 & 1.2529 & 0.7423 & 1.3143 & 0.5896 & 1.0129 & 1.0012 & 1.1086 & 1.1324 & 1.0096 & 1.0638 \\
\hline Avg W & 1.0824 & 1.0113 & 0.9794 & 0.8421 & 0.9463 & 1.0162 & 1.0004 & 1.0998 & 1.0614 & 0.9723 & 1.0445 \\
\hline Avg S & 0.9578 & 0.9122 & 0.7229 & 1.2445 & 0.9407 & 1.0236 & 1.0009 & 0.9136 & 1.2054 & 0.9556 & 1.0359 \\
\hline
\end{tabular}

Source: Data processed by the authors. 
- Central European countries are characterised by the worst combination, with high average GIM (1.0307) and low average GOM (0.9319).

After the index values were established and the GIM and GOM were created, we applied the DEA constraints both from an input and from an output perspective. An extended analysis of 5 inputs and 4 outputs would have led us to identify almost all DMUs as $100 \%$ efficient. The computed scenario is more relevant for our objective as it identifies by default less DMUs as being $100 \%$ efficient. In addition, the synthetised model is more adequate for our analysis than an extended scenario, also because it respects what the specific literature, starting with Bowlin (1998: 18), argues: the number of DMUs should be at least three times higher than the total number of inputs and outputs. If less than three DMUs per input and output variable are included in the data set, there is a danger that an excessive number of DMUs will be considered efficient because of an inadequate number of degrees of freedom. In our case, the number of DMUs collected (17) is more than 6: (1 input +1 output) multiplied by 3 .

\section{RESULTS AND DISCUSSION}

The DEA evaluation of public expenditures' efficiency can be achieved by assimilating public sector activities, such as healthcare, to a production process that transforms inputs into outputs. We used the index values obtained in a scatter chart to compare input-output pairs of values. Figure 1 illustrates the efficiency frontier and the countries placed on it and inside its borders.

We expected to find three efficient countries, namely the ones placed on the efficiency frontier: Sweden (grey circle), the UK (black circle) and Romania (black triangle). Sweden and the UK are characterised by below average input values and by above average output values, while Romania has the lowest GIM and below 1 GOM. Figure 1 also shows that Spain (grey horizontal line) is very close to the efficiency frontier. However, it can't be considered as $100 \%$

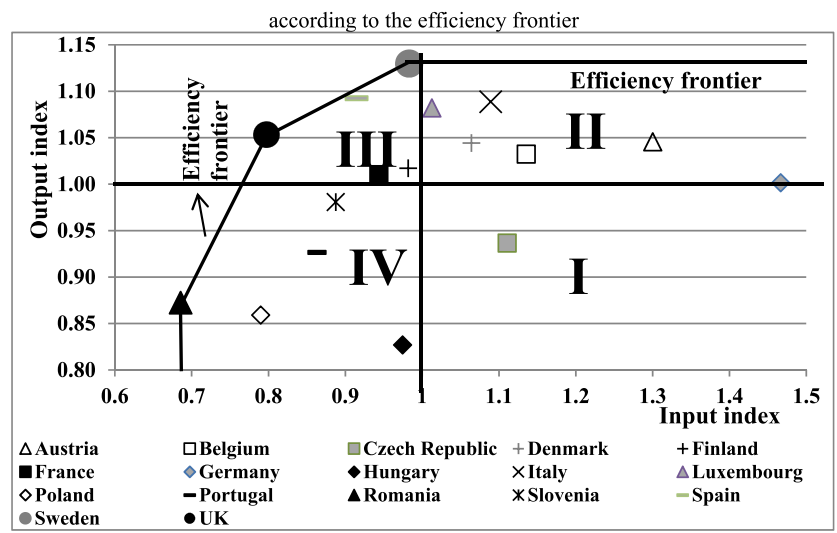

Figure 1. The input-output spread of countries' index value according to the efficiency frontier Source: Data processed by the authors. 
efficient, especially for the input orientation analysis. As seen in Table 2, its input-oriented score is of 0.9757 , while the output-oriented score is 0.9917 .

According to the obtained index values, the average in both cases is 1 and is represented by two perpendicular lines that cut Figure 1 in four areas. Besides the efficient ones, the other 14 countries included in the study are enveloped by the frontier and they will record a certain degree of inefficiency.

The most inefficient health systems are found in the countries characterised by high input levels and low output levels. These are the states placed on the right side of the average vertical line and below the average horizontal line, in the first quadrant. In Figure 1, only Czech Republic (grey square) is with the pair of coordinates $(1.1108 ; 0.9366)$. The member of the SSC group, Czech Republic is a welfare state with a continental European social model and a universal health system. Even so, it is proved to be in both input and output analysis as the antepenultimate state (rank 15).

The Beveridge countries are found on the left and upper side of the chart (quadrant III), while the Bismarck ones are widespread and obtain lower efficiency scores than the DT states, especially for the input-oriented analysis. They are large resource consumers which do not reach the expected results (most countries are found on the right side of the chart - quadrants I and II).

If we consider the other two distributions of countries, the geographical position and the historical accession to the EU, we do not observe a clear pattern. Still, we might state that 4 out of the 5 countries placed in quadrant IV are Central European countries characterised by the below average input allocation. The best performers situated in quadrant III are the Western and Northern countries if we allow Spain to be included in this case as a Western and not a Southern country. At the same time, all five countries placed in quadrant III are old EU members, their general sustainable economic performance being a proof that they obtain good results also with respect to the healthcare efficiency.

If we expect that the high values of the output variables reveal a positive feature of a country's health system, the potential years of life lost and the infant mortality rate should display values as low as possible to generate good results for that country. As expressed by Afonso - Aubyn (2005), the DEA techniques imply that the outputs are measured in such a way that more is better. Starting from these assumptions, we adjusted the variables so that the higher values to show good characteristics. The changes are described in Section 4.

Table 2 displays the efficiency scores and shows that one of the best performers is Sweden. It uses financial, material and human resources below the average (0.9832) and has the highest average GOM, by almost $13 \%$ higher than the overall GOM. This Beveridge state had a very good infant survival rate, an excellent perceived health status and a low number of years of potential life lost. It is also in the top three performers with respect to life expectancy. The UK has similar results as Sweden. However, it has a more balanced ratio between the input allocation and the output results. Its average input and output pair of coordinates $(0.797,1.053)$ prove the previous statement. The UK is not necessarily characterised by low financial resources spent on health, but by moderate allocation of other type of medical resources, like: number of CT and MRI machines, curative beds, number of consultations and health personnel.

Romania is probably the most surprising country identified as efficient. In our analysis, it is placed on the frontier of efficiency especially because it has the lowest average GIM as compared to all the other countries. The resources allocated are with almost $32 \%$ less than the average input. Even though the output (0.8725) is below the average GOM, many of the output values 
Table 2. DEA allocative and technical efficiency scores for the Bismarck and Beveridge type countries

\begin{tabular}{|c|c|c|c|c|}
\hline \multirow[b]{2}{*}{ Decision unit } & \multicolumn{2}{|l|}{ INPUT - oriented } & \multicolumn{2}{|l|}{ OUTPUT - oriented } \\
\hline & Technical efficiency score & Rank & Technical efficiency score & Rank \\
\hline Austria & 0.60961 & 16 & 0.92547 & 7 \\
\hline Belgium & 0.67892 & 14 & 0.91369 & 9 \\
\hline Czech Republic & 0.65284 & 15 & 0.82897 & 15 \\
\hline Denmark & 0.74421 & 12 & 0.92438 & 8 \\
\hline Finland & 0.78947 & 11 & 0.90082 & 10 \\
\hline France & 0.81665 & 9 & 0.83244 & 14 \\
\hline Germany & 0.52187 & 17 & 0.88653 & 12 \\
\hline Hungary & 0.70352 & 13 & 0.73431 & 17 \\
\hline Italy & 0.81019 & 10 & 0.96357 & 5 \\
\hline Luxembourg & 0.85662 & 6 & 0.95781 & 6 \\
\hline Poland & 0.86800 & 5 & 0.82523 & 16 \\
\hline Portugal & 0.83296 & 8 & 0.85763 & 13 \\
\hline Romania & 1.00000 & 1 & 1.00000 & 1 \\
\hline Slovenia & 0.84779 & 7 & 0.89939 & 11 \\
\hline Spain & 0.97573 & 4 & 0.99170 & 4 \\
\hline Sweden & 1.00000 & 1 & 1.00000 & 1 \\
\hline UK & 1.00000 & 1 & 1.00000 & 1 \\
\hline Max SSC & 1.00000 & 1 & 1.00000 & 1 \\
\hline Max DT & 1.00000 & 1 & 1.00000 & 1 \\
\hline Min SSC & 0.60961 & 17 & 0.73431 & 17 \\
\hline Min DT & 0.74421 & 12 & 0.85763 & 13 \\
\hline Average & \multicolumn{2}{|l|}{0.80638} & \multicolumn{2}{|l|}{0.90835} \\
\hline SSC group average & \multicolumn{2}{|l|}{0.75558} & \multicolumn{2}{|l|}{0.88038} \\
\hline DT group average & \multicolumn{2}{|l|}{0.87894} & \multicolumn{2}{|l|}{0.94830} \\
\hline Former EU members' average & \multicolumn{2}{|l|}{0.80302} & \multicolumn{2}{|l|}{0.92950} \\
\hline New EU members' average & \multicolumn{2}{|l|}{0.81443} & \multicolumn{2}{|l|}{0.85758} \\
\hline Northern European average & \multicolumn{2}{|l|}{0.84456} & \multicolumn{2}{|l|}{0.94173} \\
\hline Southern European average & \multicolumn{2}{|l|}{0.87296} & \multicolumn{2}{|l|}{0.93763} \\
\hline Western European average & \multicolumn{2}{|l|}{0.83805} & \multicolumn{2}{|l|}{0.92598} \\
\hline Central European average & \multicolumn{2}{|l|}{0.74338} & \multicolumn{2}{|l|}{0.87141} \\
\hline
\end{tabular}

Source: Data processed by the authors. 
collected for Romania in the first years of analysis improved considerably towards the last years studied. It is the case of the infant survival rate and of the potential years of life lost. This fact contributed to record a more moderate GOM, not as low as probably expected. As seen in the literature review, Asandului et al. (2014) revealed that Romania and Bulgaria were among the efficient DMUs.

The lowest input efficiency scores are seen in Germany. Although it is a global leader in several sectors and it upholds a social security health system, our analysis showed that it is the most resource consuming country not only with respect to the financial resources, but also regarding the technological or human capacities. Figure 1 proves that Germany is placed much to the right side as it has the highest GIM, while GOM is just a little bit above the average. Very low scores are also seen in the case of Austria. The input orientation score is 0.60961. As in the case of Germany, Austria has also very high input allocation resources and not that high outputs.

For the output analysis, the technical scores are more homogeneous and closer to 1. Efficiency scores start at 0.73431 and is obtained in the case of Hungary. Regardless our results, Austria and Hungary are considered to be the high-income economies with a high-living standard. They have a social security healthcare system and a tuition-free university education.

Figure 1 proves that the best scores are found for the DT sample, two of the countries found efficient being included in this category. The average DT score is of 0.879 , while the average SSC score is much lower (0.756). This occurs for the input-oriented model. Although the gap in the output case is not that evident, differences exist, the DT score being of 0.948 while the SSC is 0.880 .

Many of the 14 countries that are found inefficient attain high levels of outcome with considerable use of resources. For instance, France has very high levels of health expenditures as weight into GDP. Italy, Czech Republic and Spain have a higher than average number of physicians, while Hungary, Poland, Slovenia and Luxembourg are countries with more curative care hospital beds than the overall average. The average input efficiency score was 0.80638 , suggesting that the countries could achieve, on average, roughly the same level of output with $19.36 \%$ less input. Health systems could be improved without necessarily increasing expenditures, health personnel or any other input measure. The SSC category of states has an average score, expressed as percentage, of only $75.56 \%$. The technical score of these countries is, on average, almost 12.3 percentage points lower than the average score of the DT group. Significant differences are to be observed also between the Southern countries which have a score of 0.87296 and the Central European ones which have a score of 0.74338 .

A similar description can be associated for the output-oriented dimension. The average score is above $90 \%$, which implies that with the available volume of resources, these 17 countries could have reached a $9.16 \%$ higher level of output. Regarding the two main groups of countries, the SSC one is maintaining the lowest score (0.8804) as compared to that of the DT category (0.9483).

In summary, two issues become obvious in our GIM and GOM analysis.

1. Countries with higher levels of health expenditures as a ratio into GDP, above the $\mu+\sigma / 2$ limit, tend to have lower efficiency scores than the countries with lower input levels, where $\mu$ is the average and $\sigma$ is the SD of input variables in the sample. For instance, for the average 16-year analysis, five countries with health expenditures higher than the limit mentioned before, which in our case is of $7.40 \%$, Denmark, France, Sweden, Germany and Austria, reach 
the lowest average input-oriented scores, of only 0.738 . The other 12 states, which have a moderate allocation of financial resources, display an average input-oriented score almost 10 percentage points higher, of 0.835 .

2. The Beveridge countries enjoy greater efficiency in the use of input than the Bismarck ones. This is proven not only by the actual scores, but also by the rank occupied by each country. In the output-oriented case, the first positions belong to four DT countries (Sweden and the UK plus Spain and Italy), while the last positions are associated with four SSC states Hungary (0.734), Poland (0.825), Czech Republic (0.829) and France (0.832). For the input, the last five positions belong also to SSC states: Germany (0.522), Austria (0.610), Czech Republic (0.653), Belgium (0.679) and Hungary (0.704).

Generally, the ranks obtained by the sampled EU Member States are similar in both cases. Still, we may observe some differences for Austria (the 16th place for input and the 7th place in the output hierarchy) and Poland (the 5th position in terms of input and 16th for output). If Poland spends few resources and gets low results, Austria allocates significant input to reach the desired outcome.

\section{CONCLUSIONS}

The main advantage of the non-parametric DEA methodology is that the efficiency frontier is established among the observed group based on real world data (not on ideal ones). By considering the synthetic case of GIM and GOM, only three countries were found efficient: Sweden, the UK and Romania.

The mechanisms by which the EU countries distribute funds for the health systems are very complex. Governments are involved in financing medical care and most countries use a combined system between social security contributions and direct funding. Comparisons between different EU health systems can be a useful guide for identifying the most effective way of financing health systems.

Of the two main health systems, Beveridge and Bismarck, based on the indicators used to analyse the performance of health systems, the first one is considered efficient to a greater extent than the second one. The Beveridge system has proven to be more effective with respect to the infant survival rate. The countries included in this system have a more developed system of prevention and even a better strategy aiming at ensuring the health of each citizen. The Bismarck model is characterised by compulsory insurance. The funds raised depend on the number of contributors and on the ratio between the number of such taxpayers and that of the beneficiaries of medical services. This leads to multiple problems, especially in times of high unemployment, when contributors' number drops and state intervention is required. The states included in this system are heterogeneous, some of them financing their public health needs, while others are unable to improve the quality of services.

As compared to the research of van der Zee - Kroneman (2007), according to the scores we reached, there is a difference between the two groups of states, the Beveridge category being more concentrated on the quality of outputs. The paper of van der Zee - Kroneman shows that there was not much of a difference between the two systems even though the SSH systems are considered to be more expensive, while the NHS ones have a better cost containment. This result was also found by Kozuń-Cieślak (2020). In the paper, the author came to the conclusion that 
the Bismarck-style systems perform worse in cotrolling the costs, although there was not much difference between the two systems when the inputs were expressed using health expenditure as a percentage of GDP. When computing DEA using the USD per head expenditure data at purchasing power parity, the conclusion reached was that the Beveridge-style system has a slight advantage over the Bismarckian one. The third model, which is more similar to the one developed in our paper, refers to the physical units (medical staff and equipment) as inputs and proves the significant difference between the two systems. All in all, the results reached in all these papers, including the current one, when comparing the two systems are not surprising, as the former WHO reports agreed on the overall advantage of Beveridge over the more costly Bismarck type social security systems.

When referring to the old and the new Member States and their location in Europe, the results prove that the former EU states reach higher scores than the new ones, the Southern European states are leaders in the input-oriented case and the Northern ones for the outputoriented perspective.

Our results fasten that the efficiency in this economic sector, where public provision is usually essential, is not an issue to be neglected. The states with a higher or lower degree of inefficiency embrace the idea of maintaining the same level of financial resources and reach better results. If resources are available, they should be used efficiently and prioritise the outcome. This is an output-oriented approach and is usually seen during the economic boom periods. When crisis occur, public representatives are inclined both to cut wages and to reduce the number of personnel from all public sectors, health included.

The countries that are found inefficient should be more careful with respect to the balance between how much they spend for health and how efficient their health system is in providing the expected high quality services. Investments should be made, but the results should improve for many of the selected countries.

Our study may be useful especially for the decision makers in the public administrations. However, future studies might explain why some countries are more efficient than others when it comes not only to the health provision, but also with respect to the education field. As a major part of funding is of public origin, it could be the case that the inefficient provision is to be related to public sector inefficiency.

\section{REFERENCES}

Afonso, A. - Aubyn, M. St. (2005): Non-Parametric Approaches to Education and Health Efficiency in OECD Countries. Journal of Applied Economics, VIII(2): 227-246.

Afonso, A. - Fernandes, S. (2006): Measuring Local Government Spending Efficiency: Evidence for the Lisbon Region. Regional Studies, 40(1): 39-53.

Afonso, A. - Schuknecht, L. - Tanzi, V. (2005): Public Sector Efficiency: An International Comparison. Public Choice, 123(3-4): 321-347.

Andronic, M. L. (2015): Fiscal Decentralization and Public Spending Efficiency. Braşov: Transilvania University Publishing House (in Rumanian).

Asandului, L. - Roman, M. - Fătulescu, P. (2014): The Efficiency of Healthcare Systems in Europe: A DEA Approach. Procedia Economics and Finance, 10: 261-268 (in Rumanian). 
Baba, M. C. (2016): Evaluating the Financial Performance of Companies from the Pharmaceutical Industry. Bulletin of the Transilvania University of Braşov, 9(58): 223-228.

Bowlin, W. F. (1998): Measuring Performance: An Introduction to Data Envelopment Analysis (DEA). The Journal of Cost Analysis, 15(2): 3-27.

Cheng, G. - Zervopoulos, P. D. (2014): Estimating the Technical Efficiency of Health Care Systems: A Cross-Country Comparison Using the Directional Distance Function. European Journal of Operational Research - EJOR, 238: 899-910.

Chilingerian, J. A. (1995): Evaluating Physician Efficiency in Hospitals: A Multivariate Analysis of Best Practices. European Journal of Operational Research - EJOR, 80(3): 548-574.

Coelli, T. (1996): A Guide to DEAP Version 2.1: A Data Envelopment Analysis (Computer) Program. Centre for Efficiency and Productivity Analysis. CEPA Working Paper, No. 96/08, Armidale: University of New England.

Dincă, G. - Baba, M. C. - Dincă, M. S. - Dauti, B. - Deari, F. (2017): Insolvency Risk Prediction Using the Logit and Logistic Models: Some Evidences from Romania. Economic Computation and Economic Cybernetics Studies and Research, 4(51): 139-157.

Dincă, M. S. - Dincă, G. - Andronic, M. L. (2016): Efficiency and Sustainability of Local Public Goods and Services. Case Study for Romania. Sustainability Journal, 8(8): 1-24. https://doi.org/10.3390/su8080760.

Dincă, M. S. - Dincă, G. - Andronic, M. L. (2017): The Impact of Corruption, Fiscal Evasion and Migration on Economic Development. In: Marinescu, N. (ed.): East-West Migration in the EU, pp. 77-95, Newcastle: Cambridge Scholars Publishing.

Doboş, C. (2008): Financing Health Systems in the European Union Countries. Romania in the European Context. Quality of Life Review, XIX(1-2): 107-123.

Eurostat Report (2016): Definitions and Data Collection Specifications on Health Care Statistics (NonExpenditure Data).

Evans, D. B. - Tandon, A. - Murray, C. J. L. - Lauer, J. A. (2001): Comparative Efficiency of National Health Systems: Cross National Econometric Analysis. British Medical Journal - BMJ, 323(7308): 307310.

Farrell, M. J. (1957): The Measurement of Productive Efficiency. Journal of the Royal Statistical Society JRSS, Series A (General), 120(3): 253-290.

Ferrier, G. D. - Rosko, M. D. - Valdmanis, V. G. (2006): Analysis of Uncompensated Hospital Care Using a DEA Model of Output Congestion. Health Care Management Science, 9(2): 181-188.

Hollingsworth, B. (2008): The Measurement of Efficiency and Productivity of Health Care Delivery. Health Economics, 17(10): 1107-1128.

Kozuń-Cieślak, G. (2020): Is the efficiency of the healthcare system linked to the country's economic performance? Beveridgeans versus Bismarckians. Acta Oeconomica, 70(1): 1-17. https:/doi.org/ 10.1556/032.2020.00001.

Medeiros, J. - Schwierz, C. (2015): Efficiency Estimates of Health Care Systems. EC. European Economy, Economic Papers, No. 549.

Nedelea, I. C. - Fannin, J. M. - Barnes, J. N. (2010): Analyzing Differences in Rural Hospital Efficiency: A Data Envelopment Analysis Approach. Denver: Agricultural \& Applied Economics Association.

Pîrvu, D. (2015). Corruption: Profile of Political Companies in Romania. Acta Oeconomica 65(S1): 65-82. https://doi.org/10.1556/032.65.2015.S1.5.

Thomson, S. - Mossialos, E. (2009): Private Health Insurance in the EU. Final Report prepared for the EC. LSE Health and Social Care. 
Trifan, A. - Baba, M. C. (2009): Means of Calculating the Costs in the Textile Industry using Georges Perrin (GP) Method. Textile Industry 60(5): 272-278. https://doi.org/10.35530/IT.

Varabyova, Y. - Schreyögg, J. (2013): International Comparisons of the Technical Efficiency of the Hospital Sector: Panel Data Analysis of OECD Countries Using Parametric and Non-Parametric Approaches. Heath Policy, 112(1-2): 70-79.

Van Der Zee, J. - Kroneman, M. W. (2007): Bismarck or Beveridge: A Beauty Contest between Dinosaurs. BMC Health Services Research, 7(1): 94. 